\title{
ATUAÇÃO DA FISIOTERAPIA NO ESPORTE PARALÍMPICO
}

\author{
ACTION OF PHYSIOTHERAPY IN PARALYMPIC SPORT
}

ACTUACIÓN DE LA FISIOTERAPIA EN EL DEPORTE PARALÍMPICO

\section{ARTIGo de ReVISÃo \\ REVIEW ARTICLES \\ ARtículos de REVISIÓN}

Andressa Silva ${ }^{1,2}$ (Fisioterapeuta)

Roberto Vital² (Médico)

Marco Túlio de Mello ${ }^{1,2}$

(Educador Físico)

1. Departamento de Esportes, Universidade Federal de Minas Gerais, Belo Horizonte, MG, Brasil.

2. Comitê Paralímpico Brasileiro,

Brasília, DF, Brasil.

\section{Correspondência:}

Departamento de Esportes -

Universidade Federal de Minas

Gerais, Avenida Presidente Carlos

Luz, 3003/3004, Campus Pampulha,

Belo Horizonte, MG, Brasil. 31310250.

andressamello@ufmg.br

\section{RESUMO}

Cada vez mais, atletas paralímpicos têm obtido resultados expressivos em importantes competições, bem como o aparecimento de lesões musculoesqueléticas tem aumentando nesses atletas e, com isso, a ação da fisioterapia passa a ser importante e vem ganhando espaço nessa área. O objetivo do presente estudo é demonstrar as principais lesões musculoesqueléticas e a atuação do fisioterapeuta no esporte paralímpico. Observou-se que existem vários artigos publicados sobre lesões musculoesqueléticas, relacionados com a deficiência e a modalidade praticada pelo atleta. No entanto, são pouco detalhados quanto à atuação do fisioterapeuta e quais seriam as possíveis contribuições desse profissional na avaliação, no monitoramento, na intervenção e na prevenção das lesões em atletas paralímpicos. Pode-se concluir que o fisioterapeuta é um profissional de extrema relevância para a reabilitação de lesões. Contudo, as informações sobre sua atuação no esporte paralímpico ainda são restritas no que se refere às áreas nas quais pode atuar e auxiliar o atleta paralímpico.

Descritores: modalidades de fisioterapia; esportes; traumatismos em atletas; esportes para pessoas com deficiência.

\section{ABSTRACT}

Increasingly, Paralympic athletes have been achieving impressive results in major competitions, but the occurrence of musculoskeletal injuries in these athletes is also increasing. As a result, the action of physiotherapy is becoming more important and more widespread in this field. The purpose of this study is to outline the main musculoskeletal injuries and the role of the physiotherapist in Paralympic sport. There have been several published articles on musculoskeletal injuries related to disability and the modality of sport practiced by the athlete. However, these give few details on the action of the physiotherapist, and the possible contributions of this professional to the assessment, monitoring, intervention, and prevention of injuries in Paralympic athletes. It can be concluded that the work of the physiotherapist is extremely important for the rehabilitation of injuries. However, information about their action in Paralympic sport, and the areas in which they can act and help the Paralympic athlete, is still limited.

Keywords: physical therapy modalities; sports; athletic injuries; sports for persons with disabilities.

\section{RESUMEN}

Cada vez más, los atletas paralímpicos han logrado resultados expresivos en competiciones importantes, asi como la aparición de lesiones musculoesqueléticas está aumentando en estos atletas y, por lo tanto, el papel de la fisioterapia se vuelve importante y se está volviendo más popular en esta área. El objetivo de este estudio es demostrar las principales lesiones musculoesqueléticas y el papel del fisioterapeuta en el deporte paralímpico. Se ha observado que hay varios artículos publicados sobre lesiones musculoesqueléticas relacionadas con la discapacidad y el deporte practicado por el atleta. Sin embargo, hay pocos detalles en cuanto a la actuación del fisioterapeuta y cuáles serían las posibles contribuciones de estos profesionales en la evaluación, el seguimiento, la intervención y la prevención de lesiones en los atletas paralímpicos. Se puede concluir que el fisioterapeuta es un profesional sumamente importante para la rehabilitación de lesiones. No obstante, la información sobre su actuación en el deporte paralímpico sigue restringida en relación con las áreas en que puede actuar y ayudar al atleta paralímpico.

Descriptores: modalidades de fisioterapia; deportes; traumatismos en atletas; deportes para personas con discapacidad.

\section{INTRODUÇÃO}

Nos últimos anos a prática esportiva para grupos de pessoas com deficiência, passou a integrar o esporte de alto rendimento, atingindo níveis elevados de competição, o que tem aumentado o número de lesões esportivas nessa população e leva estudiosos da área a investigar as causas e consequências para os atletas com deficiência ${ }^{1-3}$. Alguns estudos na área de lesão esportiva em atletas com deficiência já foram publicados relatando as lesões que ocorrem em atletas em algumas modalidades paralímpicas ${ }^{1,4}$.

Reynolds et al..$^{5}$ destacaram a partir das Paralímpiadas de Barcelona que o fisioterapeuta é um profissional imprescindível no suporte de atletas com deficiência que praticam as modalidades paralímpicas, atuado com os demais membros da equipe médica na manutenção e recuperação da saúde consequentemente na melhora do rendimento esportivo. 
Recentemente Grant et al. ${ }^{6}$ também descreveram sobre a importância da fisioterapia esportiva nos Jogos Olímpicos de Londres, em 2012. Os autores destacaram que a demanda de trabalho do fisioterapeuta põe em evidência as necessidades desse profissional neste cenário esportivo, proporcionando, desta forma, uma visão sobre as razões pelas quais os atletas buscam apoio da fisioterapia durante a realização dos Jogos Olímpicos e consequentemente nos Jogos Paralímpicos.

Esse número elevado de lesões coloca o fisioterapia cada vez mais presente na área esportiva adaptada ou não e com uma atuação imprescindível na equipe de saúde que cuida do atleta, seja ele amador ou profissional, atuando na avaliação funcional dos atletas, no tratamento de condições patológicas do sistema musculoesquelético e na prevenção de lesões decorrentes da prática esportiva, com o intuito de minimizar as recidivas e retornar esse atleta o mais rápido possível e com segurança dentro dos limites fisiológicos e clínicos pós-lesão.

Levando em consideração que o fisioterapeuta é de suma importância no processo de avaliação física-funcional, tratamento e prevenção de lesões, no retorno ao esporte e no acompanhamento nos treinos e em competições, até o presente momento, poucas são as informações disponíveis na literatura sobre o trabalho desenvolvido por profissionais de fisioterapia junto a atletas do esporte Paralímpico, sendo assim, o objetivo do presente estudo será demonstrar as principais lesões musculoesqueléticas e a atuação do fisioterapeuta no esporte Paralímpico. A presente revisão poderá nortear os futuros fisioterapeutas que possam a vir trabalhar no esporte paralímpico e outros profissionais envolvidos na área, uma vez que, o Brasil irá sediar os próximos Jogos Paralímpicos RIO 2016 e pretende ficar entre as 5 primeiras posições no quadro de medalhas.

\section{O esporte paralímpico}

O esporte adaptado surgiu durante o processo de reabilitação dos militares ingleses envolvidos em guerra, buscando atender às necessidades das pessoas com deficiência, favorecendo a inclusão social, além de contribuir para a sua inserção no mundo esportivo. Em 1944, o neurocirurgião, Ludwig Guttmann, utilizou o esporte como parte do processo de reabilitação dos pacientes na Unidade de Lesões Medulares de Stoke Mandeville, na Inglaterra ${ }^{7}$ Na ocasião, o esporte era utilizado para melhorar a qualidade de vida e a condição psicológica dessas pessoas, sendo um elemento motivador para a integração entre pacientes no ambiente hospitalar ${ }^{8}$.

A primeira competição oficial para atletas em cadeira de rodas aconteceu em julho de 1948, no hospital de Stoke Mandeville, coincidindo com a data da abertura dos Jogos Olímpicos em Londres. Somente em 1952, atletas com deficiência da Holanda passaram a competir nas disputas de Stoke Mandeville e, juntamente com os ingleses fundaram a International Stoke Mandeville Games Federation (ISMGF - Federação Internacional dos Jogos de Stoke Mandeville), dando início ao movimento esportivo internacional, hoje conhecido como Movimento Paralímpico ${ }^{9}$. Os jogos Paralímpicos incluem atletas com deficiências físicas, mentais e visuais, sendo uma competição que ocorre a cada 4 anos, normalmente ocorrendo, no mesmo ano e logo após a realização dos Jogos Olímpicos.

Desde a Paralímpiada de 2000, na cidade de Sidney, o Brasil é um dos países que vem apresentando grande evolução nos Jogos Paralímpicos sendo que, desde Atlanta (1996) até Londres (2012), apresentou as seguintes classificações / colocações: Atlanta 37a, Sidney 24a, Atenas 14a ${ }^{\text {, Pequim }} 9^{a}$ e Londres 7a. Cabe destacar que a última competição foi considerada a maior edição dos Jogos Paralímpicos, com 4200 atletas e 160 países participantes e o Brasil participou com 180 atletas. São 22 modalidades que fazem parte dos jogos paralímpicos de verão: atletismo, natação, halterofilismo, bocha, esgrima em cadeira de rodas, vôlei sentado, goalball, hipismo, futebol de 5, futebol de 7, basquete em cadeira de rodas, tênis de mesa, tênis em cadeira de rodas, judô, paracanoagem, ciclismo, remo, rugby, tiro com arco, tiro esportivo, tiro com arco e triatlo ${ }^{10}$.

\section{Lesões musculoesqueléticas no esporte paralímpico}

O número de atletas com deficiência que participam de esportes organizados e da popularidade dos Jogos Paralímpicos é cada vez maior em todo o mundo. Apesar deste interesse crescente e o fato de que a participação em esportes coloca o atleta em risco de lesões, há poucos estudos sobre padrões de lesão, fatores de risco e estratégias de prevenção de lesões em atletas com deficiência ${ }^{11}$.

A participação de atletas com deficiência nos últimos anos em modalidades esportivas, bem como, o nível competitivo desses atletas tem sido relacionado ao aumento da incidência de lesões musculoesqueléticas ${ }^{12,13}$

No esporte Paralímpico, Vital et al..$^{14}$ relataram que treinos intensivos, com o objetivo de melhorar o desempenho durante as competições, levam ao surgimento de lesões resultantes da prática esportiva, chamadas de lesões desportivas. Na maioria dos casos a natureza das lesões é de origem musculoesquelética. Quando essas lesões não forem diagnosticadas e tratadas adequadamente, podem evoluir para patologias crônicas, impossibilitando o atleta a progredir no esporte. Vanlandewijck ${ }^{15}$ declarou que um dos aspectos que necessita ser pesquisados a respeito de atletas com deficiência é o entendimento dos mecanismos causais das lesões esportivas e que mesmo com a crescente popularização do esporte paralímpico, ainda existe uma lacuna em pesquisas dos padrões e fatores de risco de lesões para algumas modalidades. No entanto, as lesões não possuem origem simplesmente quanto a pratica do esporte, mas também, são potencializadas e agravadas devido ao tipo de deficiência associado a modalidade esportiva praticada e ao nível de aptidão física e de capacidade técnica para realização do gesto esportivo.

No presente estudo realizou-se um levantamento bibliográfico e verificou-se a existência de um número considerável de estudos epidemiológicos sobre lesões em atletas com deficiência, os quais surgiram com o intuito de informar aos atletas e treinadores os riscos lesionais das modalidades, prover informações para a equipe de saúde e assegurar atendimento adequado e dar base para a realização de um trabalho preventivo para reduzir a incidência de lesões esportivas nessa população ${ }^{16}$

O primeiro estudo a relatar as lesões musculoesqueléticas foi nos Jogos Paralímpicos de Seoul em 1988 e foi publicado que 51\% dos atletas da Delegação do Canadá sofreram lesões musculoesqueléticas, sendo que os ombros, a região da coluna lombar e o joelho foram as partes do corpo mais comumente afetadas ${ }^{17}$.

Posteriormente, Reynolds e colaboradores ${ }^{5}$, descreveram que durante os Jogos Paralímpicos de Barcelona em 1992 a Delegação da Inglaterra teve os ombros, a região da coluna cervical e da lombar como as regiões mais afetadas pelas lesões musculoesqueléticas.

Para descrever as lesões dos tecidos moles sofridas pelos atletas que competiram pela Delegação Paralímpica dos Estados Unidos nos Jogos Paralímpicos de Atlanta de 1996, Nyland et al. ${ }^{18}$, avaliaram 304 atletas de 17 modalidades, relataram que 254 atletas tiveram lesões de tecidos moles e concluíram que essas lesões dependeram muito do tipo de deficiência e sugerem que o uso de dispositivos adaptativos para a competição associado com os fatores específicos dos esportes e a deficiência dos atletas, estão relacionadas com o desenvolvimento de lesões dos tecidos moles. 
Ferrara et al. ${ }^{19}$ investigaram em seu estudo o número e o tipo de lesões que ocorreram para atletas com deficiência entre os 1990-1996 dos atletas norte-americanos que participaram dos Jogos Mundiais 1990, Jogos Paralímpicos de Barcelona de 1992, do Campeonato Mundial de Atletismo de 1994 e dos Jogos Paralímpicos de Atenas 1996, sendo que os estiramentos musculares foram os problemas mais comuns e os locais do corpo mais acometidos foram a coluna e o complexo do ombro, seguido pelo membros inferiores.

Para os atletas que participam dos Jogos Paralímpicos de Verão, as escoriações, entorses e contusões são as mais comuns, no entanto, a localização das lesões parece depender da deficiência e da modalidade praticada. Assim, fatores como tipo de deficiência, modalidade esportiva praticada e nível técnico do atleta, de aptidão física, tempo de recuperação, qualidade do sono ${ }^{20}$ entre as sessões de treinamento aparentam ser determinantes para traçar um perfil das lesões esportivas no esporte Paralímpico. Lesões de membros inferiores são mais comuns em atletas com deficiência visual, amputados e paralisia cerebral, já lesões de membros superiores são mais frequentes em atletas que usam cadeira de rodas ${ }^{21}$

Por outro lado, Webborn et al. ${ }^{22}$ escreveram um estudo sobre as lesões nos Jogos Paralímpicos de Inverno de 2002, demonstrando um total de 39 lesões envolvendo os atletas, sendo que a maioria das lesões foram traumáticas (entorses e fraturas) decorrentes principalmente das modalidades de esqui alpino e hóquei no trenó.

Willick et al. ${ }^{23}$ realizaram um estudo prospectivo de coorte para caracterizar a incidência e a natureza das lesões durante os Jogos Paralímpicos, de Londres, em 2012 e descreveram que incidência geral de lesão foi de 12,7 lesões/1000-atletas dia. No geral, 51,5\% das lesões eram novas e decorrentes de lesões traumáticas agudas. A região mais lesionada (percentagem de todas as lesões) foi o ombro (17,7\%), seguido pelo pulso/mão (11,4\%), o cotovelo (8,8\%) e o joelho (7,9\%).

Durante os Jogos Paralímpicos de Londres (2012) o Comitê Paralímpico Internacional implementou um novo sistema de vigilância de lesões e doenças com base na Web (WEB-IISS) para uso da equipe de saúde em eventos esportivos e também para registrar a incidência, as características das lesões e as doenças nos atletas durante aquela edição dos Jogos Paralímpicos. Nesse sistema foram registrados 3.565 atletas de 160 países dos 164 participantes que foram acompanhados diariamente durante um período de 14 dias. As taxas de incidência de lesões durante o período de competição foi de 12,1/1.000 atletas por dia. Lesões dos membros superiores (35\%), em particular do ombro (17\%) foram os mais comuns ${ }^{24}$

Um estudo realizado com a Delegação Brasileira de Atletismo Paralímpico demonstra que as principais queixas musculoesqueléticas foram as mialgias seguidas pelas artralgias e tendinopatias, tendo os membros inferiores mais acometidos durante o Mundial Paralímpico de Atletismo em Christchurch Nova Zelândia 2011¹.

Uma sequência de estudos realizados por Magno e colaboradores sobre lesões em atletas com deficiência visual demonstraram que na modalidade de natação os deficientes visuais apresentaram um elevado número de lesões por overuse, associada com espasmo muscular na coluna vertebral e tendinopatia nos ombros². No estudo sobre os deficientes visuais que praticam a modalidade de Futebol ${ }^{5}$ constataram que as lesões traumáticas representaram 80\% e lesões por overuse 20\%, sendo a maioria delas nos membros inferiores e tendo como destaque o joelho ${ }^{4}$. Já no estudo realizado com deficientes visuais da modalidade de atletismo constatou-se que as lesões por overuse representaram $82 \%$ e as lesões traumáticas representaram 18\%, tendo também como destaque uma maior frequência de lesões nos membros inferiores ${ }^{25}$.

Fagher e Lexell ${ }^{11}$ realizaram uma revisão sistemática sobre a epi- demiologia das lesões esportivas em atletas com deficiência e constataram que as lesões de membros inferiores foram mais comuns em atletas que praticam as modalidades em pé, enquanto que lesões de membros superiores foram mais prevalentes em atletas praticantes de modalidade em cadeira de rodas. No entanto, relataram que poucos estudos definiram as modalidades ou a deficiência, o que tornou difícil determinar fatores de risco específicos.

Webborn e Emery ${ }^{3}$ relataram que o Comitê Paralímpico Internacional realizou um estudo coorte prospectivo, sendo o maior até o momento, envolvendo 49.910 atletas, os resultados identificaram grandes diferenças entre as modalidades e destacaram a necessidade de estudos longitudinais específicos nas modalidades e não apenas estudos durante as competições. Destaca também a importância de analisar os padrões das lesões e os fatores de risco para lesão nesta população, para informar adequadamente as estratégias de prevenção de lesões e ainda, realizar estudos para identificar o impacto da participação desportiva nas lesões e na saúde futura dos atletas com deficiência.

Silva et al. ${ }^{26}$ realizaram um estudo na modalidade de atletismo que avaliou a força muscular de flexão e extensão dos joelhos por meio do dinamômetro isocinético em três momentos durante um ano de acompanhamento e correlacionaram com as lesões nos membros inferiores, concluíram que o desequilíbrio muscular está relacionado ao relato de queixas do joelho e da coxa, nas três avaliações realizadas. Os autores sugerem que a avaliação do relato de queixas realizada simultaneamente com a avaliação isocinética possam contribuir para identificar, prevenir e determinar o tratamento de lesões musculoesqueléticas em atletas do Para-atletismo.

A atuação do fisioterapeuta no esporte exerce um papel amplo por também prestar assistência com a manutenção e recuperação de lesões, com isso surge a necessidade da criação de sistemas de controle e registro de lesões para fornecer informações mais detalhadas sobre diagnóstico, grau de lesão e a razão pelo qual o desempenho, ou o treinamento, ou o tipo de deficiência e ou o tipo de órtese ou prótese utilizadas durante a prática esportiva ou vida diária podem favorecer no aparecimento de uma lesão ${ }^{6}$

Os atletas com deficiência podem estar mais susceptíveis a sofrer lesões esportivas quando estão presentes os fatores intrínsecos como comprometimento, por exemplo, da força, do equilíbrio, da marcha, da coordenação, da sensibilidade, do tônus, da flexibilidade e desalinhamento anatômico, muitas vezes levando à sobrecarga de segmentos não afetados funcionalmente.

\section{ATUAÇÃO DA FISIOTERAPIA NO ESPORTE PARALÍMPICO}

\section{Atuação na classificação funcional}

O fisioterapeuta também faz parte da banca de classificação funcional, onde juntamente com médico, terapeutas ocupacionais, psicólogos e educadores físicos realizam uma avaliação física e funcional detalhada do atleta para classificá-lo dentro das modalidades paraolímpicas ${ }^{27}$. Antes de participar de qualquer competição, o atleta com deficiência deve obrigatoriamente passar por esta classificação funcional28.

Conceitualmente, a classificação constitui-se em um fator de nivelamento entre os aspectos da capacidade física e competitiva, colocando as deficiências semelhantes em um grupo determinado. Isso permite igualar a competição entre indivíduos com várias sequelas de deficiência, pois o sistema de classificação eficiente é o pré-requisito para uma competição mais equiparada ${ }^{29}$.

A classificação esportiva de atletas com deficiência sustenta o princípio do jogo limpo, viabilizando a estrutura da competição. Tem por objetivo garantir condições de igualdade nas competições, considerando-se o nível de comprometimento do atleta. Podemos considerar que a 
classificação do esporte paralímpico é dividida em classificação médica (oftalmológica) para deficientes visuais, classificação funcional para os deficientes físicos e classificação intelectual para deficientes mentais.

A classificação esportiva para pessoas com deficiência visual é a única atualmente determinada estritamente pela avaliação médica. O classificador deve ser um médico oftalmologista credenciado pela Federação Internacional de Esportes para Cegos (IBSA) e a avaliação baseia-se em critérios estabelecidos na determinação da acuidade e do campo visual do atleta, de ambos os olhos, com a melhor correção (lentes de contato ou corretivas). Esta classificação esportiva é dividida em três categorias: B1 - Cegos totais; B2 - são deficientes visuais com baixa visão e B3 - deficientes visuais com um nível de visão maior.

A classificação intelectual é realizada para os atletas com deficiência mental sendo realizada por psicólogos ou médicos psiquiatras a partir de testes cognitivos, no entanto, as modalidades em que participam atletas com deficiência mental.

Já em classificação funcional utilizada para deficientes físicos, está baseada na avaliação da força muscular, qualidade e quantidade de massa muscular, equilíbrio, destreza, habilidade esportiva ${ }^{30}$, e é neste modelo de classificação que o Fisioterapeuta faz parte da equipe para avaliar a funcionalidade, juntamente com o profissional de Educação Física que avalia a parte de técnica esportiva. Cada esporte determina seu próprio sistema de classificação, baseado nas habilidades funcionais identificando as áreas chaves que afetam o desempenho para a performance básica do esporte escolhido. A habilidade funcional necessária independe do nível de habilidade ou treinamento adquirido.

Nesse sentido os números de classes são determinados de acordo com o respectivo esporte e possíveis habilidades funcionais em atletas com diferentes deficiências. Torna-se então essencial que um atleta que compete em dois ou mais esportes receba uma classificação diferenciada para cada um. A necessidade de troca de classe precisa ser continuamente revista com base nas diferenças funcionais e na performance. As regras de classificação são parte das regras técnicas do esporte.

\section{Atuação junto ao atleta paralímpico}

- O fisioterapeuta esportivo exerce um papel importante no esporte Paralímpico, que inicia na indicação e na apresentação do esporte adaptado as pessoas com deficiência, ainda no processo de reabilitação do paciente. Já no esporte, o fisioterapeuta atua na avaliação, na prevenção e no tratamento de lesões musculoesqueléticas decorrentes do esporte e ainda, faz parte na área de classificação funcional.

- O primeiro registro na literatura sobre a participação do fisioterapeuta na equipe de saúde foi nos Jogos Paralímpicos de Barcelona em 1992, no qual a Delegação da Inglaterra composta por 205 atletas, levou uma equipe de saúde composta por 12 profissionais, sendo que 7 eram fisioterapeutas, e ainda, relataram que carga de trabalho da fisioterapia foi elevada e descreveram que a massagem terapêutica como um dos recursos mais utilizados com os atletas antes a após as competições, seguido pelos recursos de eletrotermoterapia ${ }^{5}$.

Recentemente, Silva e colaboradores ${ }^{1}$ foram os únicos autores a destacar detalhadamente a atuação da fisioterapia no esporte paralímpico na Delegação Brasileira de Atletismo em uma competição internacional, no qual essa delegação foi composta por 34 atletas e tinham 2 fisioterapeutas e um médico na equipe de saúde. Eles registraram as queixas musculoesqueléticas por 21 dias e descreveram que foram realizados 428 atendimentos fisioterapêuticos e também mostraram quais foram os recursos terapêuticos mais utilizados, dando destaque para a crioterapia, a massagem terapêutica, seguidos pelo ultrassom e TENS, tanto antes quanto depois das provas disputadas.
No Brasil, o Comitê Paralímpico Brasileiro (CPB) tem fisioterapeutas em suas delegações desde a Paralímpiada de Atlanta 1996 (60 atletas), com 2 fisioterapeutas, na Paralímpiada de Sidney 2000 (64 atletas) 3 fisioterapeutas, na Paralímpiada de Atenas 2004 (98 atletas) 5 fisioterapeutas, na Paralímpiada de Pequim 2008 (188 atletas) 14 fisioterapeutas, Paralímpiada de Londres (180 atletas) 16 fisioterapeutas, sendo que nos últimos Jogos Paranamericanos de Toronto 2015, a equipe foi composta por 24 fisioterapeutas. Nesses grandes eventos uma clínica de fisioterapia é montada com toda a estrutura necessária num espaço fornecido pelo CPB para atender a todos os atletas da delegação que tenham lesões agudas ou crônicas em decorrência da prática esportiva.

Também cabe ressaltar que o CPB investe no setor de fisioterapia anualmente, onde os fisioterapeutas participam no acompanhamento tanto dos treinamentos quanto das competições nacionais e internacionais dos atletas das equipes permanente de Atletismo, Natação, Halterofilismo, Esgrima em Cadeira de Rodas e o Tiro esportivo que são suportadas pelo CPB. As demais modalidades paralímpicas também tem fisioterapeutas vinculadas a elas, no entanto, são administradas e suportadas por suas confederações.

No CPB o fisioterapeuta faz parte de uma equipe transdisciplinar composta por profissionais médicos, enfermeiros, educadores físicos, massoterapeutas, técnicos de enfermagem, psicólogos e terapeutas ocupacionais, sendo que para o atendimento de fisioterapia tem uma estrutura necessária para o atendimento ao atleta, no qual atua na avaliação, no monitoramento, na intervenção e na prevenção de lesões. Para isso, equipamentos de eletrotermofototerapia (Ultrasom, TENS, Laser, correntes combinadas, FES), macas, colchonetes, pesos livres, bolas, equipamentos para treino de equilíbrio, therabands e bandagens são disponibilizados pelo CPB e podem ser solicitadas a qualquer momento que o fisioterapeuta da equipe julgar necessário, tanto em treinamento quanto nas viagens sejam elas nacionais ou internacionais.

Tendo em vista que, o esporte paralímpico em geral abrange uma ampla variedade de exigências dos sistemas orgânicos, próximo ou, muitas vezes, além da capacidade de assimilação desses sistemas, cada modalidade esportiva apresenta características biomecânicas que impõe cargas sobre o sistema musculoesquelético. Essas condições propiciam o surgimento de lesões específicas a cada modalidade e também conforme as sequelas apresentadas pelo atleta com deficiência, surgindo a partir disso a necessidade de monitoramento, diagnóstico precoce, reabilitação e prevenção.

Com isso, a complexidade do Esporte Paralímpico e a necessidade do alto rendimento, por parte dos atletas, provocaram o aumento da prevalência e incidência de lesões, comprometendo a periodização planejada pelos técnicos e preparadores físicos e causando preocupações para atletas e comissão técnica em todas as esferas de rendimento. O fato de interromperem o processo evolutivo das adaptações sistemáticas impostas pelo treinamento e comprometer a participação e rendimento nas competições, talvez seja, a grande meta para evolução dos métodos, técnicas e equipamentos que são utilizados pela fisioterapia para o tratamento do atleta. Pois caso seja viabilizado um tempo de retorno mais rápido e com segurança para o atleta, a perda ou o decréscimo da aptidão física e da técnica possam ser minimizados.

Portanto, surge a necessidade de implementação de programas interdisciplinares e transdisciplinares que visem minimização das lesões e que sejam solucionadas de maneira eficaz e definitiva, para que o atleta recupere no menor tempo possível sua plena capacidade e também o seu desempenho esportivo e competitivo. Diante disso, no processo de treinamento, a reabilitação, envolve 
quatro grandes áreas que podem ser implementadas no esporte paralímpico, sendo elas: monitoramento, avaliação, intervenção e prevenção de leões, tendo, cada uma dessas áreas um importante papel para que haja controle e redução de lesões e recidivas, devolvendo e/ou garantindo ao atleta seu melhor nível de desempenho em treinamentos e competições.

Em relação ao monitoramento, é preciso ter um controle sobre o aparecimento de lesões e suas possíveis causas. Já a avaliação é de suma importância para controle e registro dos acontecimentos e do nível de aptidão física e funcional dos atletas, a qual pode ser realizada em ambulatório, nos treinos ou competiçõe, e/ou em laboratórios.

As avaliações devem ter um suporte científico, baseadas em protocolos descritos na literatura como, por exemplo, o uso do dinamômetro isocinético que tem se mostrado um ótimo instrumento para o controle do equilíbrio muscular dos atletas, minimizando o risco de lesões musculoesqueléticas.

No âmbito de prevenção de lesões, torna-se fundamental o entendimento dos fatores extrínsecos como tipo de treinamento, tipo de piso, indumentária, implementos, tipo de cadeira de rodas, próteses e órteses, condições climáticas e dos fatores intrínsecos como desequilíbrios musculares, alterações biomecânicas, características das sequelas, déficit de força, flexibilidade, composição corporal, nível de condicionamento físico, lesões agudos e crônicas, também devem fazer parte da prevenção e sempre em conjunto com uma equipa transdisciplinar.

Esse conhecimento facilitaria o entendimento dos mecanismos de desenvolvimento das lesões musculoesqueléticas e dos fatores predisponentes a essas lesões permitindo intervenções transdisciplinares específicas no contexto da prevenção e no processo de reabilitação.

\section{CONSIDERAÇÕES FINAIS}

Diante disso, podemos concluir que as lesões musculo-esqueléticas que os atletas Paralímpicos podem sofrer são diversas, no entanto, informações sobre a atuação do fisioterapeuta no Esporte Paralímpico ainda é restrita, não se encontram relatos em relação as possíveis áreas de atuação e como colaborar com o atleta Paralímpico. Isso pode ser em decorrência da formação curricular e acadêmica oferecida nos cursos de graduação em Fisioterapia que não oferecem acesso a essas informações durante a graduação.

Assim, sugere-se o incentivo a publicação de mais artigos científicos na área, bem como a oferta de um maior número de cursos na formação de fisioterapeutas a nível de graduação ou pós-graduação, com o intuito de disseminar o conhecimento na área do esporte paralímpico e assim consolidar profissionais com aprofundada capacidade técnica e de conhecimento especifico voltado ao Esporte Paralímpico para que se tenha um atendimento de excelência ao atleta com deficiência, atuando numa equipe transdisciplinar, e assim, contribuir para o desenvolvimento do Esporte Paralímpico e ainda, consolidar a atuação da nossa profissão nesta área de atuação, que, por sua vez ainda é carente de profissionais qualificados.

Outro ponto que deve ser mencionado é o impulso na área do esporte adaptado após a escolha do Brasil como sede dos Jogos Paralímpicos de 2016, no Rio de Janeiro, o que garante vagas para atletas em todas as modalidades paralímpicas e consequentemente um maior número de atletas estarão competindo e assim justificando mais uma vez a necessidade de bons profissionais de fisioterapia que possam colaborar e atuar durante a realização dos jogos na cidade do Rio de Janeiro.

\section{AGRADECIMENTOS}

Os autores gostariam de agradecer o apoio da Fundação de Amparo a Pesquisa do Estado de Minas Gerais e a Academia Paralímpica Brasileira do Comitê Paralímpico Brasileiro pelo apoio recebido.

Todos os autores declararam não haver qualquer potencial conflito de interesses referente a este artigo.

CONTRIBUIÇõES DOS AUTORES: AS (0000-0001-8155-4723)* foi responsável pela escrita, busca de informações científicas, revisou e aprovou a versão final do artigo. RV (0000-0003-0063-2262)* contribuiu com a escrita e discussão da parte médica e de lesões musculares, revisou e aprovou a versão final. MTM (0000-0003-3896-2208)* se dedicou a escrita, discussão da parte escrita, revisou e aprovou a versão final. *Número ORCID (Open Researcher and Contributor ID).

\section{REFERÊNCIAS}

1. Silva A, Mattiello SM, Peterson R, Zanca GG, Vital R, Itiro R, et al. Musculoskeletal complaints and physiotherapeutic, procedures in the Brazilian Paralympic Delegation during the Paralympic athletics world championship in 2011. Rev Bras Med Esporte. 2013;19(4):256-9.

2. Magno e Silva M, Bilzon J, Duarte E, Gorla J, Vital R Sport injuries in elite paralympic swimmers with visual impairment. J Athl Train. 2013;48(4):493-8.

3. Webborn N, Emery C. Descriptive epidemiology of paralympic sports injuries. PM R. 2014;6(8 Suppl):S18-22.

4. Magno e Silva MP, Morato MP, Bilzon JL, Duarte E. Sports injuries in Brazilian blind footballers. Int J Sports Med. 2013;34(3):239-43

5. Reynolds J, Stirk A, Thomas A. Geary F. Paralympics--Barcelona 1992. Br J Sports Med. 1994;28(1):14-7.

6. Grant ME, Steffen K, Glasgow P, Phillips N, Booth L, Galligan M. The role of sports physiotherapy at the London 2012 Olympic Games. Br J Sports Med. 2014;48(1):63-70.

7. Parsons A, Winckler C. Esporte e a pessoa com deficiência- contexto histórico. In: De Mello MT, Winckler C. Esporte paralímpico. São Paulo: Atheneu; 2012. p. 3-14.

8. Bailey S. Athlete first: a history of the paralympic movement. Chichester: John Wiley and Sons; 2008.

9. Steadward RD, Peterson C. Paralympics where heroes come. Canadá: DW Frieses Ltda; 1997.

10. Comitê Paralímpico Brasileiro. Disponível em: http://www.cpb.org.br/. [Acesso em Janeiro de 2015].

11. Fagher K, Lexell J. Sports-related injuries in athletes with disabilities. Scand J Med Sci Sports. 2014;24(5):e320-31

12. Laurino CFS, Lopes AD, Mano KS, Cohen M, Abdalla RJ. Lesões músculo-esqueléticas no atletismo Rev Bras Ortop. 2000;35(9):364-8

13. Silva MPM, Duarte E, Silva AAC, Silva HGPV, Vital R. Aspectos das lesões esportivas em atletas com deficiência visual. Rev Bras Med Esporte. 2011;17(5):319-23.

14. Vital R, Silva HGP, Sousa RPA, Nascimento RB, Rocha EA, Miranda HF, et al. Lesões traumato-ortopédicas nos atletas paraolímpicos. Rev Bras Med Esporte. 2007;13(3):165-8.

15. Vanlandewijck Y. Sport science in the paralympic movement. J Rehabil Res Dev. 2006;43(7):17-24.

16. Hamer, P. Disability sport. In: Caine C, Lindner K, Caine D. Epidemiology of sports injuries. Champaign, IL: Human Kinetics; 1996
17. Burnham RS, Newell E, Steadward R. Sports medicine for the physically disabled: the Canadian team experience at the 1988 Seoul Paralympic Games. Clin J Sports Med. 1991;1:193-6.

18. Nyland J, Snouse SL, Anderson M, Kelly T, Sterling JC. Soft tissue injuries to USA paralympians at the 1996 summer games. Arch Phys Med Rehabil. 2000;81(3):368-73.

19. Ferrara MS, Palutsis GR, Snouse S, Davis RW. A longitudinal study of injuries to athletes with disabilities. Int J Sports Med. 2000;21(3):221-4.

20. Silva A, Queiroz SS, Winckler C, Vital R, Sousa RA, Fagundes V, et al. Sleep quality evaluation, chronotype, sleepiness and anxiety of Paralympic Brazilian Athletes: Beijing 2008 Paralympic Games. Br J Sports Med. 2012;46(2):150-4.

21. Ferrara MS, Peterson CL. Injuries to athletes with disabilities: identifying injury patterns. Sports Med. 2000;30(2):137-43.

22. Webborn N, Willick S, Reeser JC. Injuries among disabled athletes during the 2002 Winter Paralympic Games. Med Sci Sports Exerc. 2006;38(5):811-5.

23. Willick SE, Webborn N, Emery C, Blauwet CA, Pit-Grosheide P, Stomphorst J, et al. The epidemiology of injuries at the London 2012 Paralympic Games. Br J Sports Med. 2013;47(7):426-32.

24. Derman W, Schwellnus M, Jordaan E, Blauwet CA, Emery C, Pit-Grosheide P, et al. Illness and injury in athletes during the competition period at the London 2012 Paralympic Games: development and implementation of a web-based surveillance system (WEB-IISS) for team medical staff. Br J Sports Med. 2013;47(7):420-5.

25. Magno E Silva MP, Winckler C, Costa E Silva AA, Bilzon J, Duarte E. Sports injuries in paralympic track and field athletes with visual impairment. Med Sci Sports Exerc. 2013;45(5):908-13.

26. Silva A, Zanca G, Alves ES, Lemos VA, Gávea SA, Winckler C, Mattiello SM, Peterson R, Vital R, Tufik S, Mello MT. Isokinetic assessment and musculoskeletal complaints in paralympic athletes: a longitudina study. Am J Phys Med Rehabil. 2015;94(10):768-74.

27. Freitas PS, Santos SS. Fundamentos Básicos da Classificação Esportiva para Atletas Paralímpicos. In: De Mello MT, Winckler C. Esporte Paralímpico. São Paulo. Editora Atheneu; 2012. p. 3-14.

28. Ferrara MS, Davis RW. Disability sports and medical professionals. Athl Ther Today. 1997:2(1):7-9.

29. Silva A, Mello MT. Esportes e classificação funcional paraolímpica. In: Esportes e atividades físicas inclusivas. Niterói: Intertexto; 2009. p. 53-96.

30. Davis RW. Classification: a form of athlete evaluation. Athl Ther Today. 1997;2(1):11-5. 